\section{Zur Klärung in der Puerperalfieberfrage.} Von Prof. Heinrieh Fritsch in Breslau.

\section{I.}

Es macht einen eigenthümlichen Eindruck, dass die Geburtshelfer scheinbar noch nicht ïber den Infectionsmodus bei den Wochenbettkrankheiten einig sind. Während in der Chirurgie die Billroth'schen Ausdrïcke Contact- und Spontan-Infection sich eingeführt haben, streiten sich die Geburtshelfer noch $1 \mathrm{~m}$ das Wort "Selbstinfection." Die Einen bexiehen fast alle Fälle von fieberhaften Wochenbettserkrankungen auf die Selbstinfection, ja sie diagnosticiren geradezu Selbstinfection als eine Krankheit, während Audere sagen: "Selbstinfection giebt es nicht!" Betrachtet man die Sache genau, so sind wir Alle derselben Meinung, und das Wort, der Nane ist es, der dem Einen passend dem Anderen unpassend erscheint.

Darïber dürfte wohl kein Zweifel mehr sein, dass Infectionsstoffe weder in gesunden Blute, noch in den intacten Geweben siclı nachweisen lassen. Fleischstücke und Blut, dem lebenden gesunden Organisonus mit bacteriologischer Sachkenntniss entuommen und am sterilen Orte aufbewahrt, verfaulen nicht. Wer das Gegentheil annimmt oder durch Experimente beweisen will, beherrscht eben die Technik nicht. Freilich bei der grossen Neigung in der Bacteriologie zu dilettiren, werden falsche Behauptungen gerade in dieser Specialität auch fernerhin !änfig sein.

Fasst man also das Wort Selbstinfection so auf, dass in dem Körper selbst das inficirende Agens vorhanden sei, dass also eine Wöchnerin, ohne irgend einen von aussen an sie gelangenden Coccus eine bacterielle Krankheit bekommen könnte, so ist diese Ansicht natïrlich falsch, und man ist berechtigt $z u$ sagen: Selbstinfection ist ein Unding!

Fasst man aber die Selbstinfection so auf, dass man damit die Fälle bezeichnet, wo die Schuld eines Dritten fehlt, nimmt man an, dass nicht durch einen in den Körper eingeimpften Infectionsstoff die Infection entsteht, sondern dass die aussen an der Körperoberfläche oder innen an der Scheidenoberfläche haftenden Coccen in eine puerperale Wunde gelangen, die Wundsecrete zur Fäulniss bringen, Ptoniaine bilden und Resorptionsfieber bedingen, so ist natïllich diese Selbstinfection der liäıfigste Infectionsmodus. Man ist bei dieser Interpretation des Wortes berechtigt zu sagen: Selbstinfection ist die häufigste Ursache der Wochenbettkrankheiten.

Die andere Art der Infection ist diejenige, wo direct durch die Hand oder das Instrnment des Operateurs eine infectiöse Masse in die Wunde eingeimpft oder in dem Wundsecret deponirt wird. Nennt mall nur diese Fälle "Infection von aussen" so ist dieser Infectionsmodus natiirlich helttontage selten. Fast unmöglich bei einem strengen Antiseptiker, und schwer denkbar bei einer Hebeamme, die mit kranken Wöchnerinnen und mit Kranken ïberhaupt nichts zu thun liatte.

Nenuen wir aber einen Infectionsfall deshalb Infection von aussen, weil ja im gesunden Körper, in dem verwundeten Gewebe selbst kein Infectionsstoff sich befand, sondern weil anch die Fänlnissbacterien nnd überhaupt alle Bacterien erst ansserhalb eines Körpers waren, ehe sie in ihn gelangen und in ihm waclisen, so rehören zul dieser Infection überhaupt alle Infectionsfälle. Wir sagen danu: Infection von aussen ist die Regel! Selbstinfection giebt es nicht!

Es läge nun uahe, einmal zu bestimmen, wo die Grenze zwischen dem "Selbst" und dem . A nssen" liegt. Ist "Anssen" Alles, was nach "dem gewöhnlichen "Sprachgebrauch ausserhalb des Körpers liegt, so wäre also z. B. eine Abscessbildung in der Blasenwand bei Cystitis, eine eitrige Periproctitis, ein übelriechender Abscess im Hunde und ein Infarct bei Pyämie eine "Selbstinfection". Und doch wird Jedermann meinen, dass die Coccen, welche diese Krankheiten zul Stande brachtell, voll aussen in den Körper kamen, z. B. bei dem Abscess in der Blasenwand durch unreinliche Katheterisation!

Wir nü̈ssten denınach die Grenze überall da zu suchen haben, wo eine intacte Oberfläche mit der natürlichen Epitheldecke liegt. Was also z. B. in der Scheide oder im Cervix oberhalb der Epitheldecke resp. auf ihr liegt, befindet sich ausserhalb des Körpers und bewirkt eine Infection von anssen. Was unterhalb der intacten Oberfläche, ohne Communication mit dem .Aussen", sich befindet liegt im Körper "selbst". Nın ist aber klar, dass keine dieser Körperoberflächen innerhalb und ausserhalb frei von Fäulnissbacterien ist. Tritt eine Verwnndung ein, bildet sich dabei Wundsecret, entsteht eine, wenn auch gering ausgedehnte Abtödtung des verwundeten Gewebes, so werden die überall vorhandenen Bacterien in dieser geeigneten Nährflüssigkeit einen Boden für ihr Wachsthum finden. Dem weder Scheide noch Portio werden so steril je sein, wie $z$. B. ein aus deın Körper selbst, nuterhalb der Epitheldecke entnommenes Stiick Gewebe.

Wir sehen also, dass bei unseren heutigen Anschauungen mit dem Worte Selbstinfection ind Infection von anssen wenig zu machen ist. Eine Eintheilung konnte wohl Semmelweiss auf diese Worte basiren, jetzt wird es unmöglich sein. Dies ist auch unbewusst dadurch anerkannt, dass fast alle Autoren, die sich mit der Frage beschäftigten, eine neue Nomenclatır $z u$ begründen und zu erfinden suchten. So sprach ich vor Jahren von direkter und indirekter, von primärer und secundärer Infection, so erfand Mikulicz die jedenfalls bessere Bezeichnung: Spontan- und Contactinfection. Andererseits hat man bei fortschreitender Erkenntniss der Infectionskrankheiten immer mehr den Standpunkt gewonnen, dass bestimmte Coccen stets bestimmte Krankheiten erzengen. Nach modernen Anschanungen gehört \&ur Bestimmung einer Species von Coccen unbedingt das Experiment, welches nachweist, dass stets eine ganz bestimmte Reaction der Gewebe auf die Infection mit dem bestimmten Coccus eintritt. Es schien uns deshalb möglich, die Puerpera.lkrankheiten nach der Art oder Eigenschaft oder der Wirkung der inficirenden Coccen einzutheilen. Ich wählte nach jahrelanger Ueberlegung die Namen: Nichtpathogene und pathogene Infection.

Indessen muss ich zugeben, dass auch diese Unterscheidung manches gegen sich hat. Wenn \% B. bei einer Entbindıng ein grosser Einriss in die Portio und die Scheide entsteht, wenn die Wunde durch eine unreine, mit Bacterien bedeckte Oberfläche verlälft, wenn die Secrete und die Wundfäche inficirt werden, wenn demnach diese Infection bei der schwierigen Localität, bei der Unmöglichkeit spontaner Reinigung und spontanen Abflnsses zu einer fortschreitenden Entzündung Veranlassung giebt, so tritt Lebensgefahr ein. Wenn also bei grosser Ausdehnung der Wunden und der ïbeln Eiterung schliesslich der Organismus dieser voll Anfang an nicht pathogenen Infection erliegt, so kann man doch den Vorgang nicht als etwas Harmloses auffassen! Freilich haben wir damit nichts dem Puerperium Besonderes beschrieben. Auch eine grosse Maschinen- oder Schussverletzung des Fusses führt zu Gangrän, auch hier bildet sich, da eine unreine Oberfläche verwundet wird und mit dem abgetödteten Gewebe communicirt, Jauchung und Infection. Nur kann man das Bein abschneiden und dadurch den Infectionsherd vom Körper alısschliessen. Die puerperalen Wunden dagegen sind nicht abzutrennen! Hier in dem natürlichen Brütofen der Scheide und des Uterus wird die Fäulniss, ohne Therapie, fortschreiten; werden durch das Wachsen der Bacterien Ptomaine gebildet und resorbirt, der Körper wird vergiftet, die Wöchnerin stirbt. Sie wird bei nicht pathogener Infection sterben, und das Criterium der Gefahrlosigkeit hat sich füu die nicht pathogenen Coccen als falsch herausgestellt.

Und werden die gefährlichsten Coccen des Leichengiftes beim Touchiren in die Scheide deponirt, folgt ihnen aber sofort der Strom desinficirender Flüssigkeit, die theils mechanisch die Coccen sammt den zersetzungsfähigen Massen entfernt, theils, ebenfalls resorbirt, noch in der Tiefe die Generationsfähigkeit der Coccen beschränkt oder vernichtet, so werden die gefährlichen Coccen unschädlich gemacht oder entfernt, die pathogene Infection hat weiter keine schädlichen Folgen. Es kann also bei nicht pathogener Infection, ohne Therapie, der Tod eintreten, und eine pathogene Infection kann bei geeigneter Therapie geheilt werden!

Bedenken wir nun noch, dass nicht etwa $z$ wei Bacterienformen in Betracht kommen, sondern höchst wahrscheinlich eine Unzahl verschiedener Species, so wird sich eine strenge Trennung in nichtpathogene und pathogene Infection nicht aufrecht erhalten lassen. Denn darüber dürfte kein $Z$ weifel sein, dass es einen Puerperalfieberpilz, wie etwa einen Typhuspilz, nicht giebt. Schon die Alten haben ja gewusst, dass Eiter von den verschiedensten Affectionen stammend, vielleicht selbst Bacterien acuter Exantheme Puerperalfieber erzeugen können. Es ist gewiss richtig, dass auch die Infection der Genitalien mit Erysipelcoccen ein Puerperalfieber bewirkt. Ja man müsste sich wundern, wenn es nicht der Fall wäre. Dass aber jedes Puerperalfieber auf Erysipelinfection beruht, ist schon deshalb nicht denkbar, weil die Aetiologie den Zusammenhang des Puerperalfiebers mit jauchenden Wunden, an denen nie Erysipel vorgekommen war, oft genug klargelegt hat.

Ich eriunere anch an die Thatsache, dass verschiedene Puerperalfieberepidemieen einen sehr verschiedenen Charakter liatten, dass, wie die Alten sagten, der Genius epidemicus verschieden war. Einmal starben alle Wöchnerinnen an septischer, rapid verlaufender Peritonitis, das andere $\mathrm{Mal}$ fanden sich nur eitrige Peritonitiden, die erst in der zweiten oder dritten Woche tödteten. In anderen Epidemieen kamen mehr Pyämieen und Endocarditiden oder wenigstens Mischformen von Septicopyämie vor. In einigen Epidemieen war der Uterus auffallend unbetheiligt, klein und gut involvirt, die Sepsis war eine allgemeine, locale Erkrankungen fehltell. In anderen Epidemieen wiederum konnte man Schritt vor Schritt die Schmerzhaftigkeit des Uterus, der Parametrien nachweisen, und es fanden sich grosse Tumescenzen der Parametrien. Einmal nur "venöse", ein andermal nur ,lymphatische" Fälle.

Es dürfte doch nach unseren hentigen Anschauungen richtig 
sein, hier stets verscliedene Coccenformen als inficirend anzunehmen. Olshausen hat gewiss Recht, wenn er z. B. für die Pyämie eiven anderen Coccus annimmt als für die Sepsis.

So babe ich z. B. in Sommer 4 Wöchnerinnen in der Klinik verloren, an einer Puerperalkrankheit, die in dieser Form sehr selten ist. Die Wöchnerinnen erkrankten erst in den späteren Wochenbettstagen, bei völlig intacten Genitalien. Sie bekamen bei andauernd holiem Fieber Muskelanschwellungen an Armen und Beinen, acute, maligne, circumscripte Oedeme. Das Bewusstsein war nicht getrübt. Die bei Lebzeiten entnommene Oedemflüssigkeit enthielt eine colossale Menge Streptococcen. Es lag hier jedenfalls eine ganz bestimmte Coccenform vor, welche dieses eigenthümliche, vom gewöhnlichen Puerperalfieber verschiedene Krankheitsbild lieferte.

Ich führe dies Alles an, um auch meinerseits zuzugeben, dass die Eintheilung in niclitpathogene und pathogene Infection viel gegen sich hat. Trotz dessen halte ich sie immer noch für besser als die alte Eintheilung in Selbstinfection und Infection von aussen. Bei dem Festhalten an dem Worte "Selbstinfection" fïhlt man mit einem gewissen Schmerz sich die Basis der modernen Proplyylaxe unter den Füssen weggezogen! Auch die Anhänger der alten Eintheilung, die ja sachlich natürlich keine wesentlich anderen Anschauungen haben und gerade wie Kaltenbach die energische Säuberung der Sclieide besonders betonen, werden gewiss zugeben, dass der Ausdruck Selbstinfection manches Bedenkliche hat.

Vielleicht, wenn eine ganze Anzalll von inficirenden Coccenformen charakterisirt ist, wird man die Puerperalkrankheiten nach der botanischen Species eintheilen können. Vielleicht gelingt es einmal, für alle verschiedenen Coccen auch verschiedene parallele Krankheiten zu erkennen. Vorläufig ist dies aber nicht der Fall, und deshalb ist auch die Eintheilung in nichtpathogene und pathogene Infection ungenau.

Sehen wir nun, dass sich gegen jede Nomenclatur und Eintheilung Einwände erhebell lassen, so wird es das Beste sein, die Wochenbettkrankheiten, wie die anderen Krankheiten, nicht nach der Aetiologie, sondern nach den klinischen Erscheinungen einzutheilen. Wir werden am besten alles "Wochenbettkrankheiten“ nennen. Dass sie alle auf Infection beruhen, bezweifelt Niemand mehr. Es ist also unnöthig, von puerperalen Infectionskrankheiten zu sprechen.

Unsere Aufgabe muss es sein, jeden einzelnen Fall auf seine Aetiologie liin möglichst genau zu untersucher. Nicht nur im allgemeinen, sondern speciell auf die Coccenform hin. In jedem Falle werden wir der lebenden Wöchnerin Blut und Wundsecrete entnehmen, die Flüssigkeit resp. die Coccen untersuchen, cultiviren und mit den Culturen experimentiren.

Aus diesen Einzelforschungen werden sich ganz sicher allmählich allgemeine Gesichtspunkte ergeben.

Was aber die Proplyylaxe anbelangt, so wird sie stets nach zwei Richtungen hin ansgeübt werden müssen. Erstens Desinfection der Hände und Instrumente! An ihnen haften jedenfalls die gefährlichsten, die patlogenen Coccen. Dafiil aber ist auch die Desinfection höchist vollkommen möglich. Hände und Instrunıente siud ohne grosse Mühe aseptisch zu machen.

$\mathrm{Z}$ weitens die Desinfection der Kreissenden. Dies ist zwar nicht so vollkommen zu erzielen, wie bei den Händen und Iustrumenten, dafïr aber sind die hier in Betracht kommenden Coccen ungefährlich, nicht pathogen. Sie werden nur dann gefährlich, wenn ihnen grosse Wunden viel Nährflüssigkeit liefern. Zu diesen grossen Wunden gehört auch die Uterushöhle. Dass sodann bei der Ungefährlichkeit dieser Bacterienformen die Desinfection der Wunden guten Erfolg haben muss, liegt auf der Hand. (Schluss folgt.) 